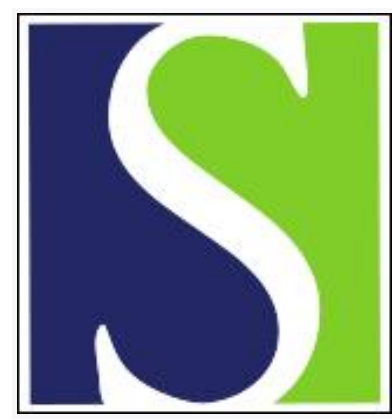

Scand J Work Environ Health 2002;28(5):349-357

https://doi.org/10.5271/sjweh.685

Issue date: Oct 2002

Medical and social prognosis for patients with perceived hypersensitivity to electricity and skin symptoms related to the use of visual display terminals

by Stenberg B, Bergdahl J, Edvardsson B, Eriksson N, Lindén G, Widman L

Affiliation: Dermatology \& Venereology, Department of Public Health and Clinical Medicine, Umeå University, SE-90185 Umeå, Sweden. berndt.stenber@vll.se

Key terms: electricity; environmental illness; follow-up study; gender; medical prognosis; patient; perceived health; perceived hypersensitivity; questionnaire; skin symptom; social prognosis; social situation; subgroup; visual display terminal

This article in PubMed: www.ncbi.nlm.nih.gov/pubmed/12432989 


\title{
Medical and social prognosis for patients with perceived hypersensitivity to electricity and skin symptoms related to the use of visual display terminals
}

\author{
by Berndt Stenberg, MD, ${ }^{1}$ Jan Bergdahl, PhD, ${ }^{2}$ Berit Edvardsson, $M D,{ }^{3}$ Nils Eriksson, $P h D,{ }^{4}$ \\ Gerd Lindén, ${ }^{5}$ Lars Widman, MD
}

\begin{abstract}
Stenberg B, Bergdahl J, Edvardsson B, Eriksson N, Lindén G, Widman L. Medical and social prognosis for patients with perceived hypersensitivity to electricity and skin symptoms related to the use of visual display terminals. Scand J Work Environ Health 2002;28(5):349-357.
\end{abstract}

\begin{abstract}
Objectives This study attempted to give a medical and social prognosis for patients with perceived "electrical sensitivity".

Methods In 1980-1998, 350 patients with electrical sensitivity were registered at the University Hospital of Northern Sweden in Umeå, Sweden. Those with hypersensitivity to electricity had multiple symptoms evoked by exposure to different electric environments. Those with skin symptoms related to the use of visual display terminals (VDT) predominantly had facial skin symptoms evoked by a VDT, television screens, or fluorescent light tubes. A questionnaire on civil status, current health status, care, treatment and other measures taken, consequences of the problem, eliciting factors, and current employment was sent to all the patients. The response rate was $73 \%$. Of the 50 respondents with hypersensitivity to electricity, $38 \%$ were men and $62 \%$ were women. Of the 200 patients with skin symptoms related to VDT use, $21.5 \%$ were men and $78.5 \%$ women.

Results More women than men had turned to caregivers, including complementary therapies. A larger proportion of patients with hypersensitivity to electricity (38\%) than those with skin symptoms related to VDT use $(17 \%)$ was no longer gainfully employed. Both groups reported a higher symptom frequency than that reported by the the general population. Over time, the medical prognosis improved in the latter group but not in the former.

Conclusions Patients with hypersensitivity to electricity, particularly women, have extensive medical problems and a considerable number of them stop working. Many patients with skin symptoms related to VDT use have a favorable prognosis. Both groups need early and consistent management.
\end{abstract}

Key terms characteristics, environmental illness, follow-up study, gender, perceived health, questionnaire, social situation, subgroups.

Facial skin symptoms related to work with a visual display terminal (VDT) were reported in Great Britain and Norway in the late 1970s (1-5). Since the first Swedish cases were reported in 1986 (6), this issue has become of major concern to local health services and a topic of considerable controversy in Sweden. Cases have also been reported in the United States $(7,8)$ and Japan (9).

In the past two decades, a group of patients with perceived "hypersensitivity to electricity" has been de- scribed (10). These patients normally report facial skin symptoms but also, general symptoms, such as fatigue and neurological symptoms including dizziness, and cognitive symptoms, such as memory loss. Patients hypersensitive to electricity attribute their symptoms to VDT work and other forms of exposure to electrical sources.

It has been suggested that patients with electrical sensitivity be divided into two subgroups, one with

1 Dermatology \& Venereology and Epidemiology, Department of Public Health and Clinical Medicine, Umeå University, Umeå, Sweden.

2 Department of Psychology, Umeå University, Umeå, Sweden.

3 Family Medicine, Department of Public Health and Clinical Medicine, Umeå University, Umeå, Sweden.

4 Department of Sociology, Umeå University, Umeå, Sweden.

5 Department of Occupational and Environmental Medicine, University Hospital of Northern Sweden, Umeå, Sweden.

Reprint requests to: Berndt Stenberg, Dermatology \& Venereology, Department of Public Health and Clinical Medicine, Umeå University, SE-901 85 Umeå, Sweden. [E-mail: berndt.stenberg@ vll.se] 
"VDT-related skin symptoms" and one with "hypersensitivity to electricity", presenting a more complex picture of symptoms and attribution $(10,11)$, both phenomena sometimes being referred to as an "environmental illness".

In a study of 201 VDT workers with skin problems, two-thirds had fewer skin complaints after an average of 8 months' follow-up (12). Eriksson et al (13) performed a 5-year follow-up of 163 patients with facial skin problems in VDT work. Symptoms appeared to be of a transitory nature for most of the subjects with isolated skin symptoms, whereas the prognosis for patients with a more complex group of symptoms was more unfavorable. The strongest risk indicators for lasting skin symptoms were reported to be psychosocial work factors (13). Measures taken in the work environment, including measures to reduce exposure to a VDT and other electrical devices, were not associated with a better prognosis.

The aims of our research project were to study the medical and social prognosis of electrical sensitivity and assess whether it is reasonable to divide patients with the condition into two subgroups, namely, patients with VDT-related skin symptoms and patients with hypersensitivity to electricity. We hypothesized that common prognostic factors may exist for different environmental syndromes of unknown or insufficiently known origin, such as hypersensitivity to electricity, the sick building syndrome, and symptoms allegedly caused by dental fillings, in particular amalgam. This study is part of a project in which patients with the aforementioned syndromes have been followed with focus on personal and external prognostic factors. Similar factors were also studied among patients with hand eczema, a well-established environmental condition.

\section{Subjects and methods}

\section{Study population}

The source population comprised patients registered at the Department of Dermatology and the Department of Occupational and Environmental Medicine at the University Hospital of Northern Sweden in Umeå, Sweden. From 1980 to 1998,350 patients with symptoms attributed to VDT work or exposure to electricity were registered at the hospital. Of these persons, we were able to contact 344 for the purposes of this study.

To be included, patients exposed to a VDT, fluorescent light tubes, television screens, or other electrical sources should experience symptoms within 24 hours of exposure. The second inclusion criterion was that the possible association between exposure and symptoms could not be ruled out or given an indisputable alternative explanation in the primary investigation. Altogether 129 referred patients were excluded due to reasons such as missing medical records, no medical examination, lack of exposure-symptom association within 24 hours, and alternative diagnoses, such as contact eczema verified by a patch test. Patients with predominantly facial skin symptoms attributed to VDT use, television screens, and fluorescent light were classified as patients with VDT-related skin symptoms. Patients who perceived symptoms, in most cases both skin and general and cognitive symptoms, attributed to electrical sources in general were classified as patients with hypersensitivity to electricity. In most cases, this distinction was easily made. The patients were classified into the two groups by a nurse (GL) from information in the medical records at the time of the follow-up. In instances in which case classification was difficult, the attribution of symptoms was considered more important than the presentation of symptoms.

Data from the patients' medical casebooks included gender, age, date of first visit, date of symptom onset, occupation, employment situation, sick leaves, symptoms, and evoking factors for symptoms. Data were missing for sick leaves, and the quality of data with respect to symptom descriptions and evoking factors varied. A questionnaire was sent to 344 patients, and 250 $(73 \%)$ of the recipients returned it. Data collection lasted from June to August 1998. The study was approved by the Ethics Committee of the Umeå University, Umeå, Sweden.

\section{Personal characteristics}

Some characteristics of the study population are shown in table 1 . Of the 50 patients with hypersensitivity to electricity who responded, $38 \%$ were men and $62 \%$ were women. Of the 200 patients with VDT-related skin symptoms, $21.5 \%$ were men and $78.5 \%$ were women. The mean age at follow-up was 49 years for the former group and 50 years for the latter. When symptoms began, $85.5 \%$ of the patients with VDT-related skin symptoms had a profession in which a VDT was commonly used. The corresponding figure was $50 \%$ among the patients hypersensitive to electricity. Allergic conditions before the start of the investigated problems were evenly distributed between the two groups, except for atopic dermatitis, which was reported significantly more often in the group with VDT-related skin symptoms $(\mathrm{P}=0.05)$. The follow-up time was significantly different in the two groups $(\mathrm{P}<0.001)$. Hypersensitivity to electricity is a phenomenon that has appeared more recently and consequently has had a shorter follow-up time than VDT-related skin symptoms. 
Table 1. Characteristics of the patient group stratified for gender and subtype of complaints (valid percentage). (VDT = visual display terminal)

\begin{tabular}{|c|c|c|c|c|c|c|c|c|c|c|c|c|}
\hline \multirow{3}{*}{ Characteristic } & \multicolumn{4}{|c|}{ Men } & \multicolumn{4}{|c|}{ Women } & \multicolumn{4}{|c|}{ Total } \\
\hline & \multicolumn{2}{|c|}{$\begin{array}{l}\text { Hypersensitivity } \\
\text { to electricity }\end{array}$} & \multicolumn{2}{|c|}{$\begin{array}{l}\text { VDT-related } \\
\text { skin symptoms }\end{array}$} & \multicolumn{2}{|c|}{$\begin{array}{l}\text { Hypersensitivity } \\
\text { to electricity }\end{array}$} & \multicolumn{2}{|c|}{$\begin{array}{l}\text { VDT-related } \\
\text { skin symptoms }\end{array}$} & \multicolumn{2}{|c|}{$\begin{array}{l}\text { Hypersensitivity } \\
\text { to electricity }{ }^{\mathrm{a}}\end{array}$} & \multicolumn{2}{|c|}{$\begin{array}{l}\text { VDT-related } \\
\text { skin symptoms }\end{array}$} \\
\hline & $\mathrm{N}$ & $\%$ & $\mathrm{~N}$ & $\%$ & $\mathrm{~N}$ & $\%$ & $\mathrm{~N}$ & $\%$ & $\mathrm{~N}$ & $\%$ & $\mathrm{~N}$ & $\%$ \\
\hline \multicolumn{13}{|l|}{ Subtype } \\
\hline Hypersensitivity to electricity & 19 & 38.0 & $\cdot$ & . & 31 & 62.0 & $\cdot$ & . & 50 & 100 & $\cdot$ & . \\
\hline VDT-related skin symptoms & . & . & 43 & 21.5 & . & . & 157 & 78.5 & . & . & 200 & 100 \\
\hline Previous asthma & 1 & 5.9 & 4 & 11.1 & 4 & 15.4 & 11 & 7.7 & 5 & 10.0 & 14 & 7.5 \\
\hline Previous allergic rhinoconjunctivitis & 4 & 23.5 & 12 & 30.8 & 6 & 24.0 & 15 & 10.6 & 10 & 20.0 & 27 & 13.5 \\
\hline Previous atopic dermatitis & - & 0 & 4 & 11.4 & 1 & 4.2 & 21 & 14.6 & 1 & 2.0 & 25 & 12.5 \\
\hline \multicolumn{13}{|l|}{ Follow-up time } \\
\hline $0-2$ years & 5 & 26.3 & 7 & 16.3 & 6 & 19.4 & 17 & 10.8 & 11 & 22.0 & 24 & 12.0 \\
\hline $3-5$ years & 12 & 63.2 & 12 & 27.9 & 13 & 41.9 & 23 & 14.6 & 25 & 50.0 & 35 & 17.5 \\
\hline $6-9$ years & 2 & 10.5 & 19 & 44.2 & 8 & 25.8 & 53 & 33.8 & 10 & 20.0 & 72 & 36.0 \\
\hline$\geq 10$ years & - & 0 & 5 & 11.6 & 4 & 12.9 & 64 & 40.8 & 4 & 8.0 & 69 & 34.5 \\
\hline
\end{tabular}

a Nineteen men (30.6\%) and 31 women (16.5\%).

${ }^{b}$ Forty-three men (69.4\%) and 157 women (83.5\%).

\section{Questionnaire}

The questionnaire was based on a previous questionnaire used in the "office illness project" in Northern Sweden (14). It contained questions on civil status, previous atopic illnesses, current health status, care, treatment and other measures taken to address the problem, consequences of the problem, precipitating factors, and current employment, as well as questions related to feelings, self-image, and the ability to cope. The results of the personality assessments are not reported in this paper.

\section{Dropout analysis}

A total of 94 persons (27\%) did not return the questionnaire. The distribution, according to gender, was similar to that for the response group. However, patients with hypersensitivity to electricity were overrepresented in the dropout group, with $45.7 \%$ in the dropout group as compared with $20 \%$ in the response group. The dropout group was subdivided into type of complaint (hypersensitivity to electricity or VDT-related skin symptoms), gender, and time of follow-up ("early visits" before 1991 and "late visits" from 1991). From the eight subgroups formed, every third patient was contacted for a telephone interview. Altogether 22 patients were interviewed, and the most common reason for nonresponse was dissatisfaction with the questionnaire, especially with questions of a psychological nature. Patients with hypersensitivity to electricity who had failed to respond had a worse health status and sense of well-being than did the response group. Their complaints, on which the primary investigation was based, were unchanged in $71.4 \%$ as compared with $37.0 \%$ in the response group. Altogether 50\% were unable to work; in the response group the corresponding proportion was $40 \%$. They were all on sick leave or on disability pension due to hypersensitivity to electricity, twice as many as in the response group with the same type of complaints. With regard to patients with VDT-related skin symptoms, the situation was the opposite. In this group, the current status was more favorable among those who did not respond than among the respondents. Of the patients interviewed, $8.3 \%$ had unchanged complaints compared with $17.1 \%$ in the response group. None of the patients were unable to work, nor were any of them on sick leave or on disability pension. In the response group, $22.5 \%$ were on sick leave or disability pension due to VDTrelated skin symptoms.

\section{Statistical methods}

Comparisons were made using the chi-square or Fischer's exact test. The Mantel-Haenszel extension test was used to test for trend. For comparing symptoms among patients at the time of follow-up and symptoms among the general population, the significance level was set at 0.01 due to multiple comparisons. For all the other comparisons, the significance level was set at 0.05 . Odds ratios (OR) and 95\% confidence intervals (95\% CI) were calculated using logistic regression in SPSS version $8.0^{\circledR}$. 


\section{Results}

\section{Characteristics in the first investigation}

The following data were compiled from the patients' medical casebooks. The distribution of recorded symptoms and evoking factors in the first investigation was dependent on the definition of the two groups, which included both symptoms and attribution of symptoms. Heating and pricking sensations on facial skin were recorded for $38 \%$ of the patients hypersensitive to electricity and for $9.5 \%$ of those with VDT-related skin symptoms. The corresponding figures for facial erythema were $24 \%$ and $67.5 \%$, respectively. Fatigue and headache were more prevalent in the group with hypersensitivity to electricity, with $32 \%$ and $22 \%$, respectively, as opposed to $7.5 \%$ and $5 \%$ for the group with VDTrelated skin symptoms. Difficulties in concentrating had a similar distribution, with $12 \%$ for patients hypersensitive to electricity as opposed to $1.5 \%$ for those with VDT-related skin symptoms. Palpitations were also recorded more often for the patients hypersensitive to electricity $(26 \%)$ than for those with VDT-related skin symptoms (1.5\%). Two-thirds of the patients hypersensitive to electricity reported that VDT use and fluorescent light were evoking factors. One-third of the patients in this group also reported aggravation of symptoms from telephone and cell phone use and from stoves. VDT use was reported as an evoking factor by $96 \%$ of the patients with VDT-related skin symptoms. Only 2 $5 \%$ reported nonlight-emitting sources as triggering factors. Already in the first investigation, a significant difference $(\mathrm{P}=0.01)$ was found between the two groups of patients with respect to total time off sick from work. As many as $12.8 \%$ of the patients hypersensitive to electricity had been on sick leave for up to 2 years, as opposed to $2.1 \%$ of those with VDT-related skin symptoms.

\section{Actions taken due to complaints and the changes in conditions}

For this part of the study, data were taken from the follow-up questionnaire. After the first investigation, most of the patients had received treatment at occupational health centers. There was a marked difference between the two patient groups with respect to other forms of care. Among the patients hypersensitive to electricity, $36 \%$ had been treated by psychologists or psychiatrists, $36 \%$ had been for dental care, and 38\% had used complementary therapies. The corresponding percentages for the patients with VDT-related skin symptoms were $6 \%(\mathrm{P}<0.001), 15 \%(\mathrm{P}=0.002)$, and $9.5 \%(\mathrm{P}<0.001)$, respectively. The higher rate of dental care among those hypersensitive to electricity corresponds with figures for the replacement of dental amalgam. At the time of the first medical examination, $32 \%$ of the patients hypersensitive electricity and $5.5 \%(\mathrm{P}<0.001)$ of those with VDT-related skin symptoms had undergone such replacement. We had no further information on the types of intervention the patients had been subject to or whether the intervention differed within the groups.

Actions taken at home and at the workplace are illustrated in figure 1 . The female patients hypersensitive to electricity exhibited a divergent pattern. Almost half of them had stopped working, and, consequently, most of the actions taken in this group refer to actions taken in the home.

\section{Situation in the follow-up}

We asked the patients to rate their perception of their current health status and sense of well-being on a 10point visual analogue scale. There were only minor differences between the two groups. A look at the symptom reports in the questionnaire, however, revealed marked differences between the two groups and also between the patients and an adult control population. The general population data were derived from an identical questionnaire returned by 2154 persons, a random sample of the Swedish population aged 18-64 years (unpublished data).

Figures 2 and 3 show the prevalence of symptoms perceived every week during the last 3 months among the men and women, respectively. Nearly all the symptoms were more prevalent among the patients hypersensitive to electricity than among those with VDT-related skin symptoms. Symptoms were more prevalent among the women than among the men, as was also the case in the population data. General and cognitive symptoms were the most prevalent among the patients hypersensitive to electricity, while skin symptoms were more equal in prevalence. Oral symptoms were also more prevalent among those hypersensitive to electricity than among those with VDT-related skin symptoms. In comparison with the general Swedish population, headache, difficulties in concentrating, eye symptoms, facial erythema, sensory symptoms, and a burning sensation in the mouth were significantly more prevalent $(\mathrm{P}<0.01)$ among the men hypersensitive to electricity. The men with VDT-related skin symptoms differed from the general population with respect to eye irritation, nasal symptoms, and facial skin symptoms. Among the women hypersensitive to electricity, all the symptoms except fatigue, headache, nausea, dry facial skin, nasal symptoms, and dry mouth were more prevalent $(\mathrm{P}<0.01)$ than in the population data. Among the women with VDT-related skin symptoms, all the symptoms 


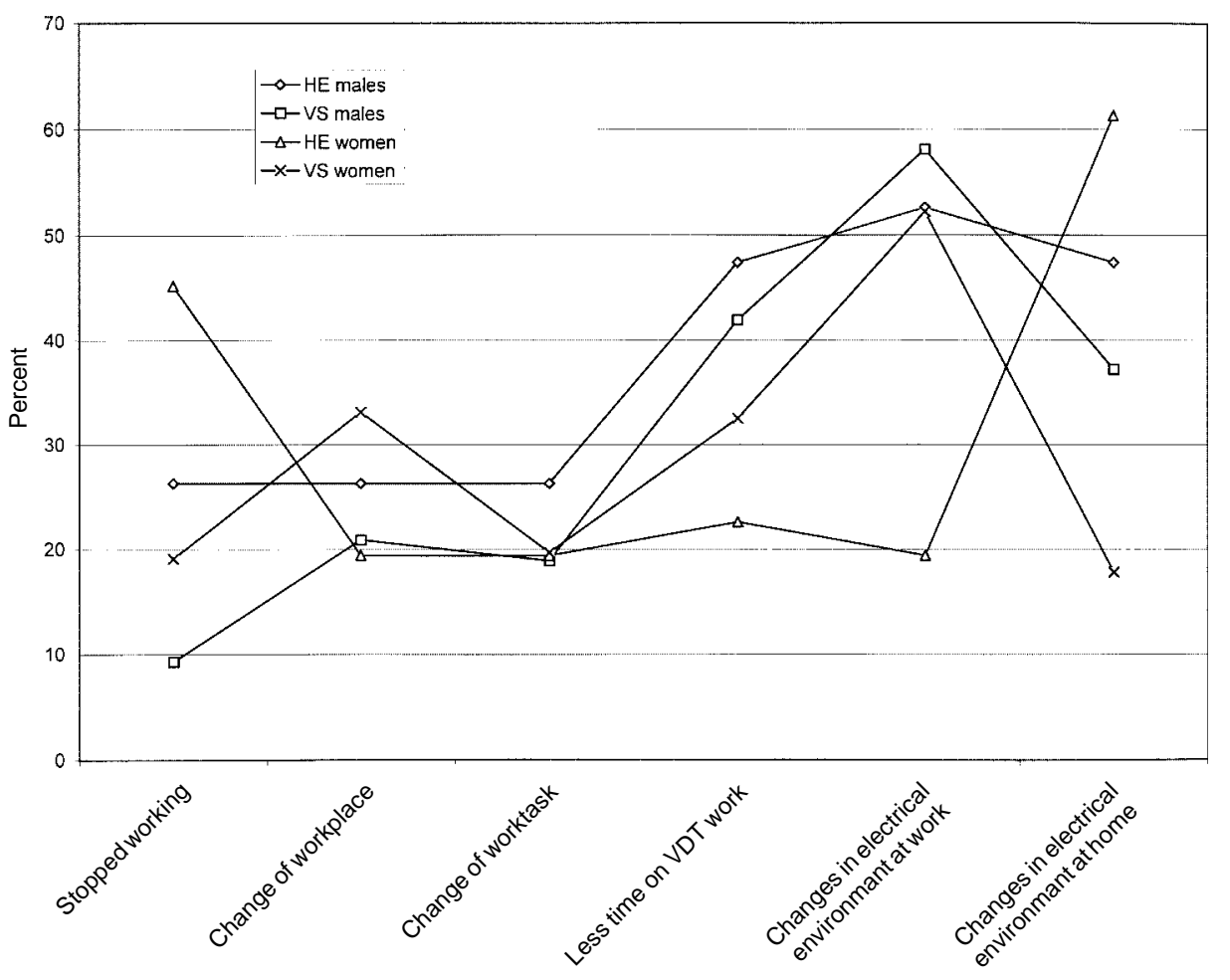

Figure 1. Actions taken due to hypersensitivity to electricity (HE) or skin symptoms related to the use of a visual display terminal (VS).

but fatigue, heavy headedness, headache, nausea, vertigo, palpitations, and nasal and oral symptoms were significantly more prevalent $(\mathrm{P}<0.01)$ than in the general population.

Perceived causes of symptoms among the patients hypersensitive to electricity were VDT work (62.0\%), exposure to television screens (54.0\%), and exposure to fluorescent light (70.0\%), light bulbs (24.0\%) and other devices or circumstances, such as cell phones, transporting vehicles, household devices, sunshine, radios, power lines, and visits to the bank and shopping centers $(42.0 \%)$. The corresponding figures for patients with VDT-related skin symptoms were $49.0 \%, 26.5 \%$, $39.5 \%, 11.5 \%$, and $30.0 \%$, respectively. The difference between the groups was significant, except for VDT work and other circumstances. Due to the different quality of data in the patient files in the first visit investigation and at the time of the follow-up, it was not possible to compute the number of patients that switched from a diagnosis of VDT-related skin symptoms to hypersensitivity to electricity, and vice versa, during the follow-up. Still, our data indicate that a number of patients did indeed switch from one symptom category to the other.

Table 2 provides a summary of the prevalence of the remaining complaints concerning hypersensitivity to electricity or VDT-related skin symptoms, work capacity, and patients on sick leave or disability pension.
There was a significant difference between the groups regarding the perceived alleviation of symptoms. Twice as many patients hypersensitive to electricity as those with VDT-related skin symptoms stated that their symptoms had remained unchanged. Complete healing was rarely reported in the group hypersensitive to electricity. In order to analyze the impact of time on the prognosis, we stratified the patients into four groups according to the follow-up time, $\geq 10$ years, 6-9 years, 3-5 years, and 0-2 years. In the group hypersensitive to electricity, two-thirds of the patients reported that their symptoms had remained unchanged or almost unchanged regardless of the length of follow-up. In the group with VDT-related skin symptoms, the figures dropped from $49.2 \%$ among those with the shortest follow-up time to $25.8 \%$ for those with a long follow-up. In the group with VDT-related skin symptoms, the test for trend was significant $(\mathrm{P}=0.01)$. After adjustment for follow-up time, the risk of having unchanged or almost unchanged complaints at the time of follow-up was significantly higher among the patients hypersensitive to electricity (OR 2.16, 95\% CI 1.04-4.47). A look at work capacity at the time of follow-up showed a striking discrepancy between the patients hypersensitive to electricity and those with VDT-related skin symptoms. Threequarters of the patients with VDT-related skin symptoms were fully capable of working, while a similar 


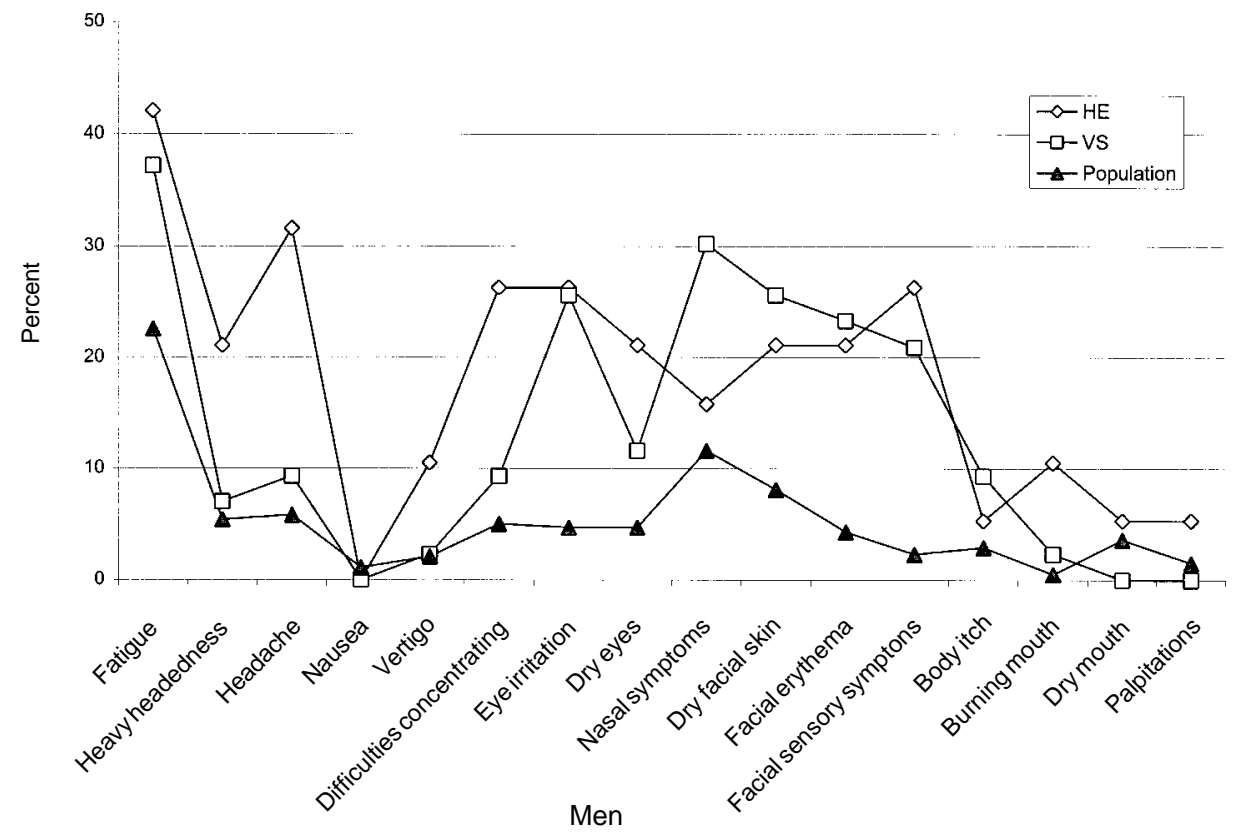

Figure 2. Weekly symptoms among the male patients with hypersensitivity to electricity ( $\mathrm{HE}$ ) and skin symptoms related to the use of a visual display terminal (VS) at follow-up and in a male control population.

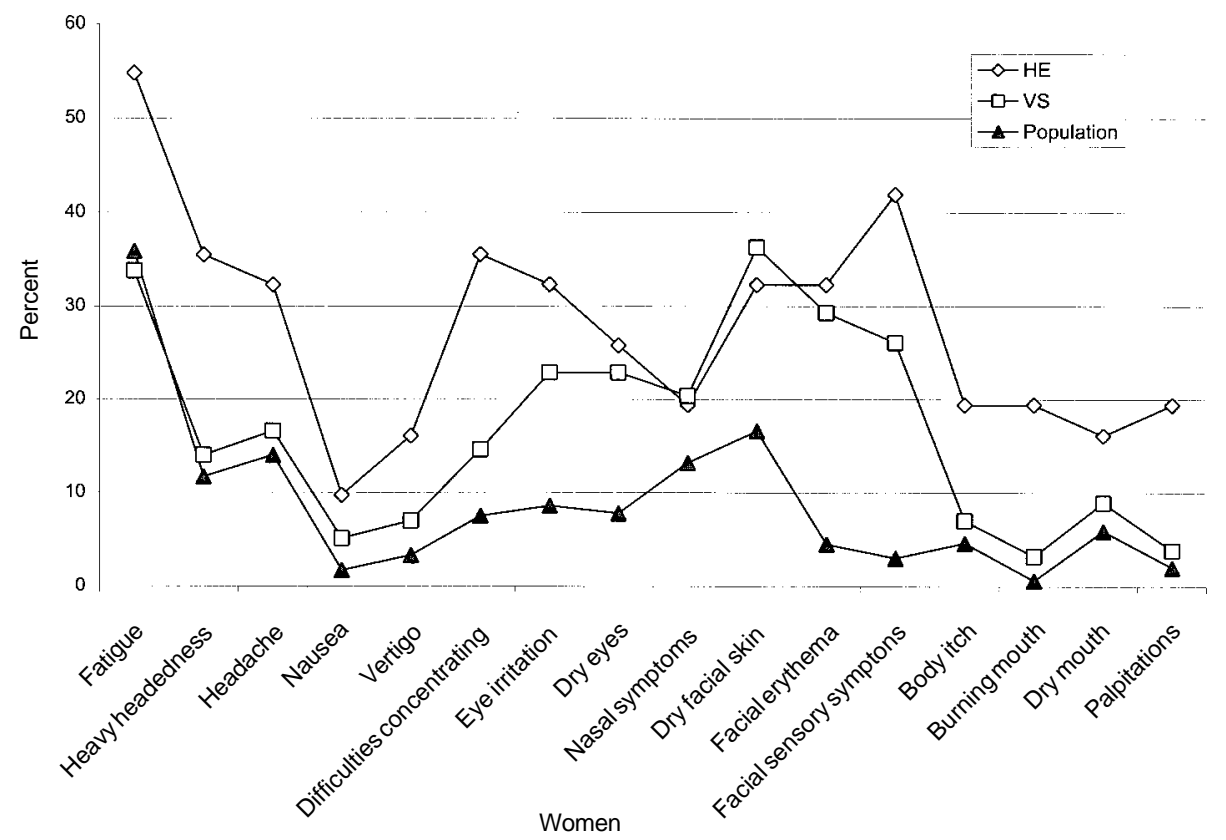

Figure 3. Weekly symptoms among the female patients with hypersensitivity to electricity (HE) and skin symptoms related to the use of a visual display terminal (VS) at follow-up and in a female control population.

proportion of patients hypersensitive to electricity was partly or completely unable to work. This difference was also reflected in higher proportions of sick leave and disability pension in the group hypersensitive to electricity. The difference between the groups was highly significant $(\mathrm{P}<0.001)$. Of the 22 patients hypersensitive to electricity reported to be on sick leave in the first investigation, only $2(9.1 \%)$ were doing full-time work at the time of the follow-up. The corresponding figures for the patients with VDT-related skin symptoms was 33 of $66(50 \%)$. The difference between the groups regarding this crude estimate of successful rehabilitation is significant $(\mathrm{P}=0.002)$. 
Table 2. Perceived health and social situation at the time of the follow-up, as stratified for type of complaint and gender (valid percentage). (VDT = visual display terminal)

\begin{tabular}{|c|c|c|c|c|c|c|c|c|c|c|c|c|}
\hline & \multicolumn{4}{|c|}{ Men } & \multicolumn{4}{|c|}{ Women } & \multicolumn{4}{|c|}{ Total } \\
\hline & \multicolumn{2}{|c|}{$\begin{array}{l}\text { Hypersensitivity } \\
\text { to electricity }\end{array}$} & \multicolumn{2}{|c|}{$\begin{array}{l}\text { VDT-related } \\
\text { skin symptoms }\end{array}$} & \multicolumn{2}{|c|}{$\begin{array}{l}\text { Hypersensitivity } \\
\text { to electricity }\end{array}$} & \multicolumn{2}{|c|}{$\begin{array}{l}\text { VDT-related } \\
\text { skin symptoms }\end{array}$} & \multicolumn{2}{|c|}{$\begin{array}{l}\text { Hypersensitivity } \\
\text { to electricity }\end{array}$} & \multicolumn{2}{|c|}{$\begin{array}{l}\text { VDT-related } \\
\text { skin symptoms }\end{array}$} \\
\hline & $\mathrm{N}$ & $\%$ & $\mathrm{~N}$ & $\%$ & $\mathrm{~N}$ & $\%$ & $\mathrm{~N}$ & $\%$ & $\mathrm{~N}$ & $\%$ & $\mathrm{~N}$ & $\%$ \\
\hline \multicolumn{13}{|l|}{ Symptoms } \\
\hline Unchanged & 5 & 27.8 & 11 & 27.5 & 12 & 42.9 & 21 & 14.3 & 17 & 37.0 & 32 & 17.1 \\
\hline Almost unchanged & 5 & 27.8 & 13 & 32.5 & 8 & 28.6 & 35 & 23.8 & 13 & 28.3 & 48 & 25.7 \\
\hline Partly changed & 8 & 44.8 & 13 & 32.5 & 6 & 21.4 & 69 & 46.9 & 14 & 30.4 & 82 & 43.9 \\
\hline Disappeared & - & 0 & 3 & 7.5 & 2 & 7.1 & 22 & 15.0 & 2 & 4.3 & 25 & 13.4 \\
\hline \multicolumn{13}{|l|}{ Work capability } \\
\hline Fully capable & 7 & 41.2 & 32 & 82.1 & 5 & 17.9 & 98 & 70.0 & 12 & 26.7 & 130 & 72.6 \\
\hline Partly capable & 5 & 29.4 & 6 & 15.4 & 10 & 35.7 & 30 & 21.4 & 15 & 33.3 & 36 & 20.1 \\
\hline Unable to do work & 5 & 29.4 & 1 & 2.6 & 13 & 46.4 & 12 & 8.6 & 18 & 40.0 & 13 & 7.3 \\
\hline $\begin{array}{l}\text { On sick leave due to VDT-related } \\
\text { skin symptoms }\end{array}$ & 6 & 31.6 & 4 & 9.3 & 8 & 25.8 & 25 & 15.9 & 14 & 28.0 & 29 & 14.5 \\
\hline $\begin{array}{l}\text { On disability pension due to } \\
\text { hypersensitivity to electricity } \\
\text { or VDT-related skin symptoms }\end{array}$ & 2 & 10.5 & 3 & 7.0 & 9 & 29.0 & 13 & 8.3 & 11 & 22.0 & 16 & 8.0 \\
\hline On disability pension for other reasons & - & 0 & 1 & 2.3 & 4 & 12.9 & 16 & 10.2 & 4 & 8.0 & 17 & 8.5 \\
\hline
\end{tabular}

\section{Discussion}

The patients under discussion were not defined by generally recognized criteria. When facial skin problems related to VDT work were first observed in Sweden and some other countries, they were often designated as "VDT-related skin symptoms" and "screen dermatitis". After the appearance of patients who attributed both skin and general somatic and cognitive symptoms to exposure to electrical sources in general, the term "hypersensitivity to electricity" was introduced. Even if it has been possible to verify that the amount of VDT work is associated with reports of facial skin symptoms (1417), the etiology of the condition is unknown. The association between symptoms and exposure to electromagnetic fields among patients "hypersensitive to electricity" has not been verified (10). In popular speech today, the term "hypersensitivity to electricity" is often used for both patient groups. Due to the lack of specific diagnostic symptoms and specific tests, the selection of patients studied in this paper was based on practical reasoning, such as attribution of symptoms to certain exposures, symptoms compatible with previous publications, and lack of an undisputed alternative explanation for the symptoms. The division into two groups was based on clinical experience (10). The criteria for separating patients hypersensitive to electricity from those with VDT-related skin symptoms in this study were of course somewhat arbitrary, and some patients may have been misclassified. In cases in which this classification was difficult, the attribution of symptoms guided the decision. A small number of patients with VDT-related skin symptoms reported nonlight-emitting sources as evoking factors. In the patients' casebooks, however, such sources were judged to be of minor importance for these patients. As the classification was done by an investigator unaware of the follow-up results, the misclassification should be nondifferential. Such misclassification dilutes the difference between the groups at followup, and the difference was thus probably underestimated. It should also be noted that the characteristics at the time of the first visit were those that the examining physician noted in the patients' case books and they were not a complete list of all symptoms and evoking factors that the patients may have experienced. The two groups partly overlap, and patients may have moved between the groups over time. In the future, perhaps different ways of stratifying the patients will provide better prognostic information.

The patients under study constituted a selected fraction of all persons experiencing VDT-related skin symptoms and hypersensitivity to electricity. There are no published follow-up studies on incident cases recruited at worksites. It can be assumed that our patients have a more unfavorable medical and social prognosis than do those who are not referred to hospital clinics. In the 1980s, when the phenomenon was new, the indications for referring patients were probably more general than today, when many cases, especially those with VDT-related skin symptoms, are handled in primary care. Early cases may therefore better reflect the average afflicted person, whereas later cases are more seriously afflicted. This difference may also explain why there has been a shift in the proportion between patients with VDT-related 
skin symptoms and those hypersensitive to electricity in our hospital departments over the years. Patients hypersensitive to electricity need more complex investigation and care.

The dropout analysis indicated that our results underestimate unfavorable prognoses among patients hypersensitive to electricity, while the opposite applies to those with VDT-related skin symptoms. Judging from the interviews, we can speculate that many strongly handicapped patients with hypersensitivity to electricity refused to respond because they were offended by the part of the questionnaire dealing with psychological aspects. Patients with VDT-related skin symptoms, on the other hand, may have chosen not to respond because their problems had diminished.

The prevalence of asthma and allergic rhinitis did not significantly differ between the two groups of patients. Atopic dermatitis, on the other hand, was more prevalent in the group with VDT-related skin symptoms. Constitutional eczema may be a risk factor for facial skin reactions to environmental exposures. We have no relevant reference figures for atopic eczema in a comparable group using the same phrasing in a questionnaire. Regarding asthma and allergic rhinitis, we used questions identical to those in the "office illness project" in northern Sweden in 1988 (14). With regard to the prevalence of asthma or rhinitis, our patients did not differ from this random sample of office workers. This finding indicates that respiratory atopic illnesses are not risk factors for the development of hypersensitivity to electricity or VDT-related skin symptoms.

Our results strongly support the clinical impression that patients can be grouped according to hypersensitivity to electricity and VDT-related skin symptoms, with different long-term prognoses. Comparing our results with those of other studies is difficult. Most studies did not divide their patients in the same manner as we did. Most published studies have included what we refer to as "hypersensitivity to electricity" and "VDTrelated skin symptoms" under the heading "hypersensitivity to electricity" or "electrical sensitivity". The proportion of each group is not known. Our findings are, however, in agreement with the findings published by Berg (12), who showed that VDT-related skin symptoms have a favorable prognosis. They are also compatible with a previous follow-up study based on the "office illness project" in northern Sweden, in which people with isolated skin symptoms had a better prognosis than did those with a greater symptom complex (13). We have not found any follow-up studies of patients with hypersensitivity to electricity. Some intervention studies have been published showing that cognitive therapy $(18,19)$ and acupuncture (20) have an effect on the symptoms of hypersensitivity to electricity, but, again, the patients included both groups in unknown proportions. No con- trolled studies have been carried out on the effect of reducing electromagnetic field exposure on symptoms. Furthermore, our results cannot be compared with those of controlled intervention studies, as our patients have been subject to numerous treatment actions and the effect of separate interventions can therefore not be evaluated.

From the onset of symptoms, each patient encounters many different kinds of care giving and is subject to different actions. Patients', physicians', and other actors' attitudes towards the problem influence the directions chosen. As the nature and causes of hypersensitivity to electricity and VDT-related skin symptoms are not fully understood, attitudes and plans for action vary and continuously change. The fact that many of our subjects, especially patients hypersensitive to electricity, sought complementary care is an indication that traditional medical care has, to some extent, failed in caring for these patients. The replacement of dental amalgam, for instance, which is not a scientifically grounded action, can also be considered an action taken by patients who do not trust in regular medical care. A recent systematic review of the use of complementary therapies by dermatological patients indicated that users of such therapies are less satisfied than nonusers with the extent of emotional support received from their physicians. The length of the disease history and the severity of illness were also positively associated with the use of complementary therapies (21).

A large proportion of the patients hypersensitive to electricity underwent a psychological or psychiatric examination and treatment. This result indicates that psychological factors may have contributed to the emergence of their syndrome or to social consequences of the syndrome. Secondary psychological reactions may, however, also explain why such a large proportion of patients hypersensitive to electricity sought our psychological or psychiatric help. The difference in this regard between patients hypersensitive to electricity and those with VDT-related skin symptoms suggests that psychological factors are more relevant in the former group. In a study of risk factors and prognostic factors such as ours, it is important that premorbid psychological traits be assessed.

More female patients hypersensitive to electricity had ceased work than those in the other groups. This observation indicates that special attention should be paid to this group in the early handling of patients and in studies of prognostic factors.

In our experience and in other descriptions of patients hypersensitive to electricity (12), VDT-related skin symptoms often precede the perception of sensitivity to electric exposure in general. If this evolution of perceived sensitivity can be stopped at an early stage, it will favorably influence the prognosis, according to 
our findings. For this reason, further studies of prognostic factors are important.

We hypothesized that there may be common prognostic factors for different environmental syndromes of unknown or insufficiently known origin, such as hypersensitivity to electricity, the sick building syndrome, and symptoms allegedly caused by dental fillings, in particular amalgam. This study is part of a project in which patients with the aforementioned syndromes have been followed with a focus on personal and external prognostic factors. Similar factors were also studied for patients with hand eczema, a well-established environmental condition.

We conclude that patients hypersensitive to electricity, in particular women, have extensive and severe medical and social problems as opposed to patients with VDT-related skin symptoms. Many patients with VDTrelated skin symptoms in fact have a good prognosis. Both groups do, however, need early and consistent management, patients hypersensitive to electricity because of the nature and extent of their problems and patients with VDT-related skin symptoms to prevent further progress. This distinction may be of value to physicians handling patients in primary care.

\section{Acknowledgments}

This study was supported by the Swedish Council for Work Life Research.

\section{References}

1. Pearce BG. Health hazards in perspective. In: Pearce BG, editor. Health hazards of VDT's? New York (NY): John Wiley \& Sons, 1984:5-12.

2. Lindén V, Rolfsen S. Video computer terminals and occupational dermatitis [letter]. Scand J Work Environ Health 1981; 7:62-7.

3. Rycroft RJG, Calnan CD. Facial rashes among visual display unit (VDU) operators. In: Pearce BG, editor. Health hazards of VDT's? New York (NY): John Wiley \& Sons, 1984:13-6.

4. Tjonn HH. Report of facial rashes among VDT operators in Norway. In: Pearce BG, editor. Health hazards of VDT's? New York (NY): John Wiley \& Sons, 1984:17-23.

5. Nielsen A. Facial rash in visual display unit operators. Contact Dermatitis 1982;8:25-8.

6. Stenberg B. A rosacea-like skin rash in VDU-operators. In:
Knave B, Widebäck P-G, editors. Work with display units 86. Amsterdam: Elsevier/North-Holland, 1987:160.

7. Feldman RL, Eaglstein WH. Terminal illness. J Am Acad Dermatol 1985;12:366.

8. Fisher AA. "Terminal" dermatitis due to computers (visual display units). Cutis 1986;37:153-4.

9. Matsunaga K, Hayakawa R, Ono Y, Hisinaga N. Facial rash in a visual display terminal operator [in Japanese]. In: Nagoya University Branch Hospital. Annual report [in Japanese]. Nagoya: Nagoya University Branch Hospital, 1988:57-61. Report no 22. Summary in English.

10. Bergqvist U, Vogel E, Aringer L, Cunningham J, Gobba F, Leitgeb N, et al. Possible health implications of subjective symptoms and electromagnetic fields: a report prepared by a European group of experts for the European Commission, DG V. Solna (Sweden): Arbetslivsinstitutet, 1997. Arbete och hälsa 1997:19.

11. Stenberg B, Lidén C. Elkänslighet och bildskärmsbesvär kräver seriös handläggning [Sensitivity to electricity and VDT-related skin symptoms call for serious management]. Läkartidningen 1999;96:5377-9.

12. Berg M. Skin problems in workers using visual display terminals. Contact Dermatitis 1988;19:335-41.

13. Eriksson N, Höög J, Stenberg B, Sandström M. Facial skin symptoms in office workers: a five year follow-up study. J Occup Environ Med 1997;39:108-18.

14. Stenberg B, Eriksson N, Hansson Mild K, Höög J, Sandström $\mathrm{M}$, Sundell J, et al. Facial skin symptoms in visual display terminal (VDT) workers: a case-referent study of personal, psychosocial, building- and VDT-related risk indicators. Int J Epidemiol 1995;24:796-803.

15. Berg M, Lidén S, Axelson O. Facial skin complaints and work at visual display units: an epidemiologic study of office employees. J Am Acad Dermatol 1990;22:621-5.

16. Bergqvist U, Wahlberg J. Skin symptoms and disease during work with visual display terminals. Contact Dermatitis 1994;30:197-204.

17. Knave BG, Wibom RI, Voss M, Hedström LD, Bergqvist UO. Work with video display terminals among office employees, I: subjective symptoms and discomfort. Scand J Work Environ Health 1985;11:457-66.

18. Andersson B, Berg M, Arnetz BB, Melin L, Langlet I, Lidén S. A cognitive-behavioral treatment of patients suffering from "electrical hypersensitivity". J Occup Environ Med 1996; 38:752-8.

19. Hillert L, Kolmodin Hedman B, Dölling BF, Arnetz BB. Cognitive behavioural therapy for patients with electric sensitivity - a multidisciplinary approach in a controlled study. Psychother Psychosom 1998;67:302-10.

20. Arnetz BB, Berg M, Anderzén I, Lundeberg T, Haker E. A nonconventional approach to the treatment of "environmental illness". J Occup Environ Med 1995;37:838-44.

21. Ernst E. The usage of complementary therapies by dermatological patients: a systematic review. Br J Dermatol 2000; 142:857-61.

Received for publication: 20 February 2002 